\title{
IoT Protocol for Accident Spotting with Medical Facility
}

\author{
Prachu J. Patil ${ }^{1}$, Ritika V. Zalke ${ }^{1}$, Kalyani R. Tumasare ${ }^{1}$, \\ Bhavana A. Shiwankar ${ }^{1}$, Shivani R. Singh ${ }^{1}$, Shailesh Sakhare ${ }^{2}$ \\ ${ }^{1}$ Department of Electronics and Telecommunication Engineering, \\ ${ }^{2}$ Assistant Professor, Department of Electronics and Telecommunication Engineering, \\ $\mathrm{J}$ D College of Engineering and Management, \\ Nagpur, India
}

\begin{abstract}
One of the many challenges that the world faces is traffic hazard. The major cause of this traffic risk is the presence of a huge number of vehicles on the road. As a result, it generates the most challenging issues, leading to an increase in the death toll due to road accidents that occur throughout the world. As a result, it necessitates the need to provide adequate transportation facilities, which will reduce the number of collisions and save human lives. The GPS, GSM, accelerometer, Arduino UNO technology, and vibration sensor are used to design and develop a vehicle accident detection model. The proposed approach is classified into three stages to prevent and detect the vehicular accidents. At the detection stage, a vibration sensor will be utilized to determine the position of the accident and to alert the user by sending SMS via the GSM module, which will include the user's data stored in Android applications. This data will be taken from the GPS module. The second phase occurs when moderate accidents occur and in such situation, the location will be detected by using a GPS module. After that, the nearby hospital receives a message about the accidents and accordingly they provide services to the accidents. At the same time, after detecting the location, a patient receives a message from the hospital urging them to take precautions. .
\end{abstract}

Based on the Internet of Things [IoT], an intelligent system has been developed to reduce the number of deaths caused by car accidents.

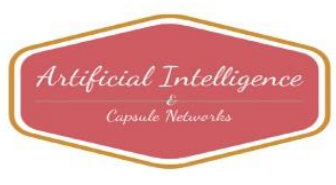


Journal of Artificial Intelligence and Capsule Networks (2021)

Vol.03/ No.02

Pages: $140-150$

http://irojournals.com/aicn/

DOI: https://doi.org/10.36548/jaicn.2021.2.006

Keywords: IoT, embedded systems, application, safety, awareness, GSM module, GPS module.

\section{INTRODUCTION:}

Transportation safety has been gaining an increasing research attention for decades as a result of ongoing deaths all across the world. One of the most significant causes of death is traffic accidents. When it comes to transportation, there are lots of applications. According to studies, the majority of deaths occur as a result of traffic accidents that occur across the world. [1-3].

There are several requirements to provide good transportation facilities for reducing the traffic hazards and save human lives. Various transportation technologies are developed and are still required for developing the optimizing technologies to reduce the ratio of road accidents. A few of the victims are children and the elderly people are crossing the roads [4-6]. A few of the causes of road accidents include poor road conditions, potholes, drunk driving, and inexperienced drivers etc. For the purpose of preventing traffic accidents, the government has enacted a number of laws and regulations. Even when wearing a helmet became mandatory, the accidents cannot be prevented completely. As a result, it necessitates the need to develop unique transportation methods to dramatically reduce the road accidents [7-9].

The main purpose of this project is to reduce the proportion of human death toll, which occurs due to road accidents. This paper aims to give a brief idea for people to use the vehicle for gaining an increased research attention. This system intends to decrease the rate of human deaths and save lives by providing medical facilities on time [10-12].

In this project, the proposed model consists of vibration sensors, accelerometer, GSM device, GPS module, and power supply. At the time of accident detection, GPS tracks the exact location of the person. These values consist of both latitude and longitude. These values are used in any database and application. The app will transfer the details to the GSM module. With the help of

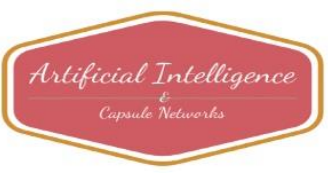


Journal of Artificial Intelligence and Capsule Networks (2021)

Vol.03/ No.02

Pages: $140-150$

http://irojournals.com/aicn/

DOI: https://doi.org/10.36548/jaicn.2021.2.006

the GSM module, we can send the message to the nearby hospital and also the medical shop. The message can be sent to the local hospital as well as the medical shop by using the GSM module. Serial communication is used to interface the communication between the GPS and GSM for further processing. The memory card stores all the GPS data as well as sensor data for accident analysis [13-15].

\section{RELATED WORK:}

Prachu Patil et al. [16] suggested the vehicle alert system based on the geographical coordinates obtained by using the GPS. The automatic system provides the alarm about the accidents and their locations. Accelerator is fitted in the car to provide the alarm and while dangerous driving such as crash or roll over has been detected. The signal from the accelerator is used for further monitoring. The location of the accident is tracked by using the geographic coordinates obtained from the microcontroller, and the information is immediately sent to the control room. The main limitation of the proposed method is the accuracy of the predicted accident information based on the GSM and GPS information.

Kalyani Tumsare et al. [18] developed the alert system based on the SMS delivered to the nearest control room. The position of the vehicle is tracked and sent to the preprogrammed numbers and then the alert message is sent to the ambulance or nearby help center. The ambulance will arrive at the location after receiving the alert message. The limitation of the system is based on the network used for alerting the system.

Shivani et al. [20] proposed the accident detection system to detect the carelessness of vehicle drivers. If the accident happens due to carelessness or not in a position to control the vehicle, the alert message will be immediately sent to the registered mobile number. The limitation of this approach is related to network issues; if the communication is delayed, there is a lower probability of protecting the individuals at a critical time. 
Journal of Artificial Intelligence and Capsule Networks (2021)

Vol.03/ No.02

Pages: $140-150$

http://irojournals.com/aicn/

DOI: https://doi.org/10.36548/jaicn.2021.2.006

Ritika et al. [17] suggested a vehicle tracking model for the accident detection system. Finally, a wireless camera is used to capture the image of accidents. Based on the obstacle detected during the accident, the ultrasonic sensor gathers the information and sends it to the microcontroller. Even though the suggested method provides optimum solution, it takes longer time to complete the entire procedure. .

Bhavana Shiwankar et al. [19] designed an accident prevention system based on the microcontroller. The telephone number of the nearest police or the closest emergency help center is stored within the ROM embedded system within the microcontroller. With the help of this method, emergency facilities can be reached at the correct time. Depending upon the microcontroller used, the accuracy of the message will reach the control room.

Shivani et al. [20] used the integrated system to send the accident alarm information to the registered email address. It will warn the driver if the vehicle is out of control based on the vibration sensor. The alert message is sent to the registered user via the mobile number and then location will be shared to the GPS system. Response time for altering the control system remains dependent upon the shared GPS location. After analyzing the related works, there is a need to develop an automated system for alerting the accident information to the control center. The proposed IoT based system gathers the vehicle information and immediately passes it to the nearest help center. This process saves the life of many people injured by the accidents.

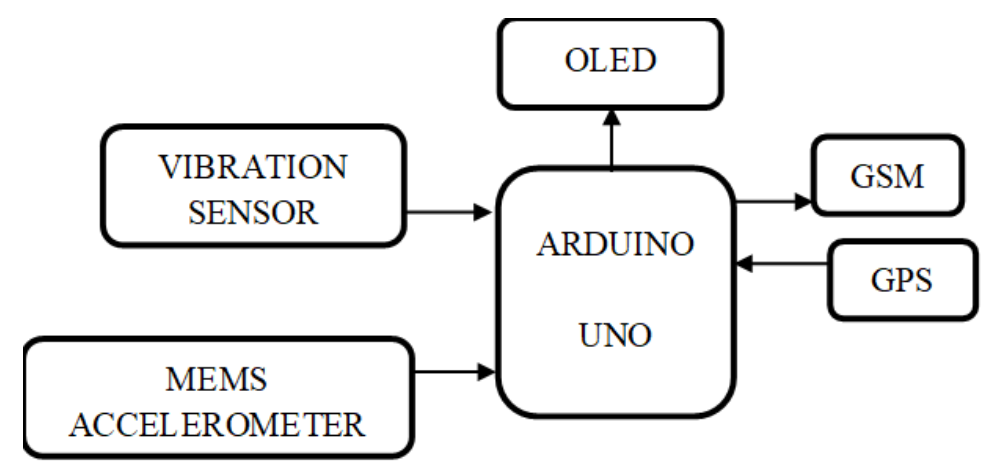

Figure: 1.1 Hardware Required

ISSN: 2582-2012 (online) 
Journal of Artificial Intelligence and Capsule Networks (2021)

Vol.03/ No.02

Pages: $140-150$

http://irojournals.com/aicn/

DOI: https://doi.org/10.36548/jaicn.2021.2.006

The above diagram of the proposed system consists of the following components such as power supply, vibration sensor, accelerometer, GPS, GSM, and OLED. The above components are provided as per the block diagram.

VIBRATION SENSOR: This sensor transmits the highly accurate vibration in a user-defined manner. This industrial automation sensor illustrates the 3 -axis of vibration data for $100 \mathrm{~ms}$ and then it calculates the dynamic range of a physical device as vibration data.

CONNECTING WIRES: Wires made up of metal will be flexible and cylindrical in nature. It is used for electrical conductivity between the two devices of an electrical circuit.

GPS: The Global Positioning System [GPS] is a satellite-based framework, which can receive a signal through the satellite. The exact time the signal will be sent. It also uses the satellite to determine its location on the earth. GSM: GSM module is a device that uses GSM mobile telephone innovation to provide a data link to the remote location. They are basically equivalent to a conventional mobile phone in the perspective of the mobile phone network, including the necessity for a SIM to identify themselves to the network. .

OLED: It allows displays to be much thinner, when compared to cathode-ray tube technology. It may be used to show the sender's message, which aids in locating the injured person's location.

MEMS ACCELEROMETER: It is a sensing element and also it contains a miniature machine verification mass that is suspended between the two equal plates. Also, it can measure the acceleration force acting on an object.

POWER SUPPLY: It can supply the power to the electric power for an electric load. It includes both the AC and DC power supply. Most of the time, it will convert the AC power to DC power. 
Journal of Artificial Intelligence and Capsule Networks (2021)

Vol.03/ No.02

Pages: $140-150$

http://irojournals.com/aicn/

DOI: https://doi.org/10.36548/jaicn.2021.2.006

\section{WORKING:}

The proposed system utilizes Arduino as the software to link the sensors for completing the activities, as well as it controls all the systems that may be employed in our project. With the help of android studio, a single application has been developed. This app showed the correct information of the injured person, which included their name, phone number, location of the accident and type of accident occurred in that place.

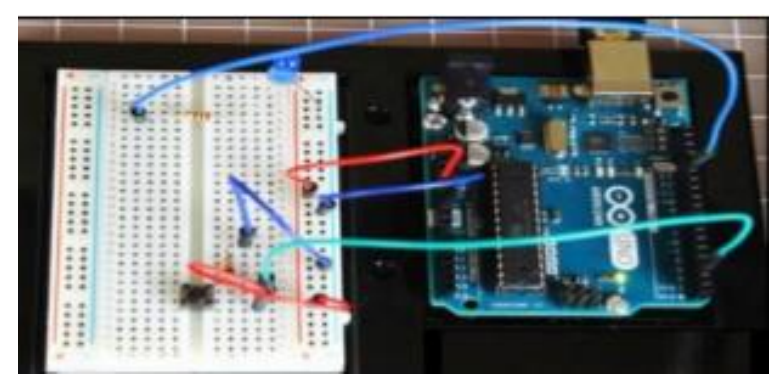

Figure: 1.2 Circuit Diagram

This system is designed for detecting the accident and alert people. This system is totally based on GSM, GPS, and Associated application. If two vehicles collide with each other, then the accident which is going to happen there will be due to the vibrational shock, which will be detected by the accelerometer and all information will be sent through the app via the registered mobile number.

According to this project, when the two vehicles collide in a severe case. The proposed model utilizes a MEMS sensor to detect the signal via the GPS module to find the exact location, which includes the longitude and latitude. After that, the sensor will send the information to the registered family member and nearby hospital through the GSM module. So, it will help us to prevent the accident and send the image to the server. As contrasted to previous systems, the proposed solution has provided numerous leads, including contraction damaged "travellers" interactivity, sending medical details to rescue personnel, and by using GPS, the actual and exact

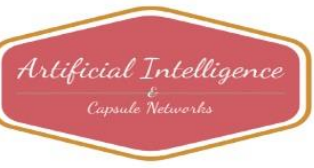


Journal of Artificial Intelligence and Capsule Networks (2021)

Vol.03/ No.02

Pages: 140-150

http://irojournals.com/aicn/

DOI: https://doi.org/10.36548/jaicn.2021.2.006

accident spot can be located. The constancy test showed that, the system is strong, accessible and serviceable. When the IoT module continues sending information about the crash occurrence until it's sure that the reception by the main office can serve to produce reports that are linked to the number of accidents and number of injured persons.

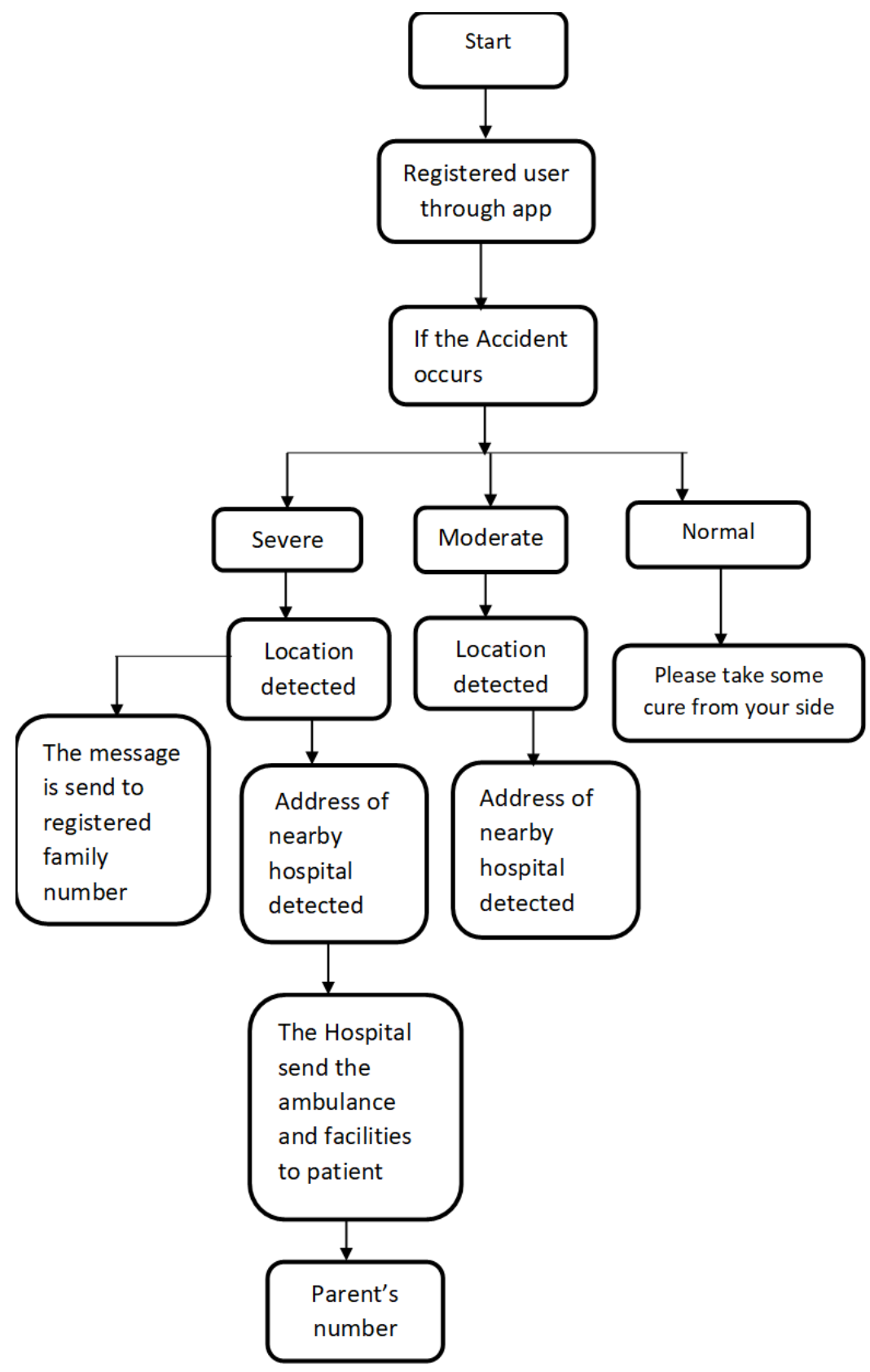

Figure: 1.3 Flowchart

ISSN: 2582-2012 (online)

146

Submitted: 11.06 .2021

Revised: 15.06 .2021

Accepted: 18.06 .2021

Published: 23.06.2021 
Journal of Artificial Intelligence and Capsule Networks (2021)

Vol.03/ No.02

Pages: 140-150

http://irojournals.com/aicn/

DOI: https://doi.org/10.36548/jaicn.2021.2.006

\section{RESULT:}

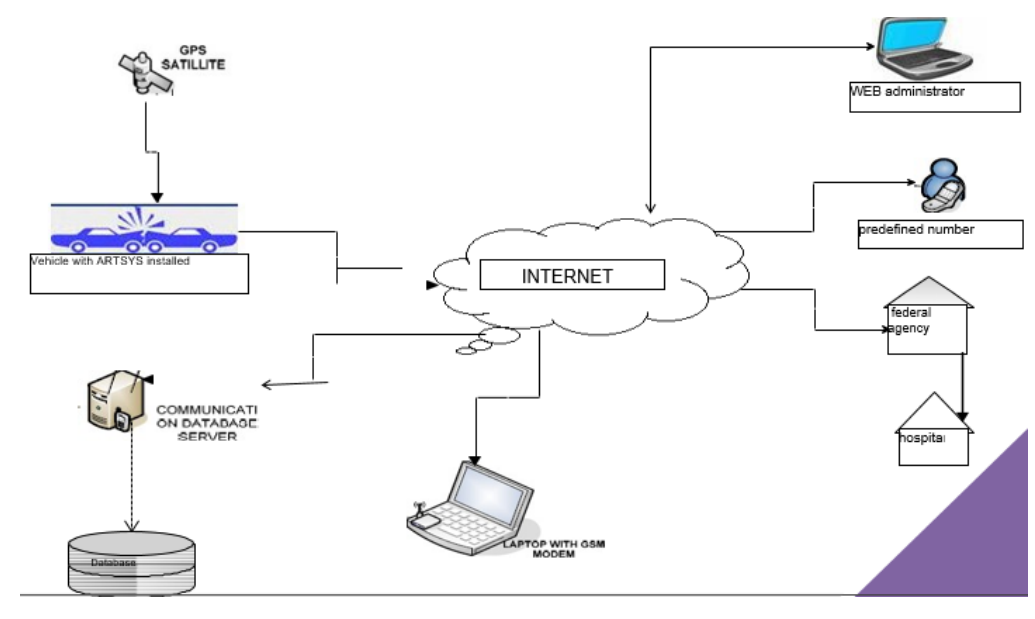

Figure: 1.4 Accident alert system

At the final result, the GPS will find the location of the accident and retrieve the most neighboring hospital, where the GSM will help to send the message in a Google Map linked to the nearest hospital based upon the distance. The suggested method is said to be extremely advantageous in terms of identifying the accident scenario and rescue the wounded individual quickly. It occurs in their respective cities to allow them to take instant action and provide as much help as possible.

\section{CONCLUSION:}

The proposed IoT system can minimize the day to day road accidental death resulting through vehicles. The system shows the maximum beneficial merits when compared to the traditional system. The proposed model minimizes the injured passengers' interaction by providing basic medical information to nearby rescue teams, recognizing exact and actual accident point/location and facilitate the routing process. Reliability testing revealed that the system is stable, available, and serviceable, particularly when the IoT device continues to send continuous information about an accident until the headquarters confirms its informatics, which can be used to create 
Journal of Artificial Intelligence and Capsule Networks (2021)

Vol.03/ No.02

Pages: $140-150$

http://irojournals.com/aicn/

DOI: https://doi.org/10.36548/jaicn.2021.2.006

statistical reports about the number of accidents, the number of injured, blood bank donors, and road conditions.

\section{FUTURE SCOPE:}

Our future scope is to improve the system and push forward towards integrating it into each vehicle through the manufacturing phase. We'll also work on another element, which we currently regard as normal and semi-severe accidents. The future work that can be done on this system is a camera module, which can be connected to the vehicle to quickly click the picture at the time of the accident and send the image to the server.

\section{REFERENCE:}

[1] Hariharakrishnan, Jayaram, and N. Bhalaji. "Adaptability Analysis of 6LoWPAN and RPL for Healthcare applications of Internet-of-Things." Journal of ISMAC 3, no. 02 (2021): 6981.

[2] World Health Organization Road Traffic Injuries Fact Sheet No 358, March 2013, Available from http://www.who.int/mediacentre/factsheets/fs358/en/ [Last accessed on 2017 Dec 16]

[3] Suma, V. "Wearable IoT based Distributed Framework for Ubiquitous Computing." Journal of Ubiquitous Computing and Communication Technologies (UCCT) 3, no. 01 (2021): 23-32.

[4] National statistics of road traffic accidents in India, September 2013, Available from http://www.jotr.in/article.asp?issn=0975- 7341; year=2013; volume=6; issue=1; page=1; page $=6$; aulast $=$ Ruikar $/$ [Last accessed on 2017 Dec 16]

[5] Adam, Edriss Eisa Babikir. "Survey on Medical Imaging of Electrical Impedance Tomography (EIT) by Variable Current Pattern Methods." Journal of ISMAC 3, no. 02 (2021): 82-95.

[6] "Vehicle Accident Detection and Reporting System Using GPS and GSM." by AboliRavindraWakure, ApurvaRajendraPatkar, IJERGS April 2014. 
Journal of Artificial Intelligence and Capsule Networks (2021)

Vol.03/ No.02

Pages: $140-150$

http://irojournals.com/aicn/

DOI: https://doi.org/10.36548/jaicn.2021.2.006

[7] Shakya, Subarna, and Lalitpur Nepal. "Computational Enhancements of Wearable Healthcare Devices on Pervasive Computing System." Journal of Ubiquitous Computing and Communication Technologies (UCCT) 2, no. 02 (2020): 98-108.

[8] Tanushree Dalai, "Emergency Alert and Service for Automotives for India", International Journal of Advanced Trends in Computer Science and Engineering (IJATCSE) Mysore India, vol. 2, no. 5, pp. 08-12, 2013.

[9] Adam, Edriss Eisa Babikir. "Evaluation of Fingerprint Liveness Detection by Machine Learning Approach-A Systematic View." Journal of ISMAC 3, no. 01 (2021): 16-30.

[10] Pin W. and Junhua W., "A Vehicle Collision Detection Algorithm at T-shaped Intersections based on Location".

[11] Himanshu C., "Recent Trends of Measurement and Development of Vibration Sensors," IEEE Sensor Journal, 2016.

[12] K. Sawant, I. Bhole, P. Kokane, P. Doiphode, Y. Thorat, "Accident Alert and Vehicle Tracking System", International Journal of Innovative Research in Computer and Communication Engineering, 4(5), pp.8619-8623,2016.

[13] M. Patil, A. Rawat, P. Singh, S. Dixit, "Accident Detection and Ambulance Control using Intelligent Traffic Control System", International Journal of Engineering Trends and Technology (IJETT) ,34(8), pp.400-404,2016.

[14] N. Chaturvedi, P. Srivastava, "Automatic Vehicle Accident Detection And Messaging System Using GPS and GSM Modems", International Journal of Scientific \& Engineering Research, 4(8), pp. 252254, 2013.

[15] S. Alagarsamy, K. Kamatchi, V. Govindaraj, "A Novel Technique for Identification of Tumor region in MR Brain Image," 3rd International conference on Electronics, Communication and Aerospace Technology (ICECA), pp. 1061-1066, 2019.

[16] Shailesh "Bhavthankar" and Prof. H. G. "Sayyed", "wireless system for vehicle accident detection and reporting using Accelerometer and GPS", vol.6, Issue 8 August 2015.

[17] Shweta V."Dhole", Supriya V. "Ramraje", Bharati B. "Bhosale", Ms. Gauri Jagtap, "Internet of things, Accident tracking and Reporting",Vol.6, 12 December 2019.

[18] Shivani Sharma, Shoney Sebastian Vol.9, 5 October 2019. 
Journal of Artificial Intelligence and Capsule Networks (2021)

Vol.03/ No.02

Pages: 140-150

http://irojournals.com/aicn/

DOI: https://doi.org/10.36548/jaicn.2021.2.006

[19] A Mane, J Rana, Vehicle Collision detection and Remote Alarm Device using Arduino, International Journal of Current Engineering and Technology, 4(3),pp.401-404,2014.

[20] A. Thiyagarajan, P. Sankar, A.R. Chandra Gurunathan, J.M. Jaffer, V. Govindaraj, S. Alagarsamy, Detection of Alzheimer's Disease Using Soft Computing Techniques," Journal of Advanced Science and Technology, 29(8s), pp. 2914-2921,2020. 